Revue des patrimoines

\title{
Les ornements liturgiques au XIX siècle : origine, fabrication et commercialisation, l'exemple du diocèse de Moulins (Allier)
}

\section{Aurore Chatard}

\section{(2) OpenEdition}

Journals

Édition électronique

URL : http://journals.openedition.org/insitu/5308

DOI : $10.4000 /$ insitu.5308

ISSN : 1630-7305

Éditeur

Ministère de la culture

Référence électronique

Aurore Chatard, « Les ornements liturgiques au XIXe siècle : origine, fabrication et commercialisation, l'exemple du diocèse de Moulins (Allier) », In Situ [En ligne], 11 | 2009, mis en ligne le 18 avril 2012,

consulté le 30 avril 2019. URL : http://journals.openedition.org/insitu/5308 ; DOI : 10.4000/insitu.5308

Ce document a été généré automatiquement le 30 avril 2019

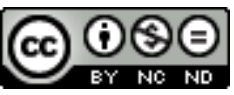

In Situ Revues des patrimoines est mis à disposition selon les termes de la licence Creative Commons Attribution - Pas d'Utilisation Commerciale - Pas de Modification 4.0 International. 


\title{
Les ornements liturgiques au XIX ${ }^{\mathrm{e}}$ siècle : origine, fabrication et commercialisation, l'exemple du diocèse de Moulins (Allier)
}

\author{
Aurore Chatard
}

\section{Introduction}

1 L'étude des ornements liturgiques constitue un sujet qui suscite un intérêt grandissant depuis la fin des années 1980. La première thèse universitaire ayant cette thématique pour axe principal a été soutenue en $1989^{1}$. Dès lors, de nombreuses études, des expositions et leurs catalogues, sont venus enrichir et consolider l'édifice des connaissances en la matière.

2 Parallèlement, la politique de recensement de l'Inventaire général du patrimoine culturel et les mesures de protection des services des Monuments historiques témoignent de ce même intérêt. Le résultat des enquêtes menées dans les régions et mis à la disposition du public dans la base de données Palissy montre une large proportion d'ornements liturgiques parmi les objets religieux étudiés et/ou protégés. Quatre mille fiches environ sont actuellement disponibles à la consultation. Les plus anciens de ces ornements remontent au VIII ${ }^{e}$ siècle : ont été repérées une étole dite de saint Pol de Léon sur lî̂le de Batz $^{2}$, et une chasuble à Chelles ${ }^{3}$; mais la grande majorité datent du XIX ${ }^{e}$ siècle. Les objets religieux de cette époque ont été longtemps considérés comme des stéréotypes vus dans leur globalité, dont la création était dénuée d'une réelle démarche artistique, et connus sous la dénomination péjorative de "saint-sulpicien». Les études thématiques laissent entrevoir une réalité différente tendant à démontrer l'existence d'une vraie recherche esthétique étroitement combinée à une histoire religieuse dont la densité à cette période ne peut être remise en question. 
3 Parmi les différentes études menées localement, une enquête a été entreprise, dans le cadre d'un master d'histoire de l'art, sur le territoire du diocèse de Moulins correspondant à l'étendue administrative du département de l'Allier ${ }^{4}$. Elle a reposé sur une opération préalable de recensement des ornements liturgiques, en collaboration étroite avec le conservateur des Antiquités et objets d'art du lieu. Pour mener cette investigation, trente-sept communes ont été choisies sur les trois cent vingt du département ${ }^{5}$. Mille sept cent quatre-vingt-six objets ont été répertoriés. Pour la plupart, ils étaient alors conservés in situ et n'avaient jamais été le sujet d'aucune étude.

Mettre au jour, tenter de dater et comprendre l'histoire d'une telle collection implique d'avoir recours à plusieurs champs de connaissances. Avant toute chose, il faut avoir une notion du vocabulaire spécifique employé pour la dénomination de chaque objet. Des compétences dans le domaine des textiles permettent de compléter la description de chacun d'eux et d'identifier les techniques utilisées pendant la période concernée par l'étude. Le poids de l'histoire politique et sociale de la France est également une composante fondamentale: après la période révolutionnaire, l'Église catholique se reconstitue au terme d'un processus long et parfois difficile, puis elle doit lutter vers la fin du siècle contre un affaiblissement du sentiment religieux. Son combat passe, entre autres, par l'image qu'elle souhaite donner, y compris à travers les arts. Ceci est d'autant plus vrai que celui qui fut à la tête du diocèse de Moulins pendant toute la seconde moitié du siècle n'était autre que Mgr de Dreux-Brézé (1811-1893), connu pour être l'évêque ayant fait le plus pour l'art français à cette période ${ }^{6}$. L'histoire régionale voire locale peut aussi apporter quelques éclaircissements. Les particularismes locaux ont souvent la vie dure au sein de l'Église malgré les tentatives d'uniformisation. Les évêques ont parfois une personnalité tellement forte que, malgré leur volonté de voir des pratiques rituelles normalisées, ils sont eux-mêmes à l'origine de nouvelles exceptions.

\section{Les ornements liturgiques : une tradition pluriséculaire}

5 La principale caractéristique commune à tous les ornements liturgiques du XIX ${ }^{\mathrm{e}}$ siècle réside dans leur appartenance à une longue tradition pluriséculaire. La terminologie, la forme et la symbolique qui leur sont attachées traduisent souvent l'ancienneté de leur origine.

\section{Origine et définitions}

6 L'expression « ornement liturgique » cache une réelle complexité quant à sa définition. À travers les siècles, de nombreux ouvrages, du plus généraliste au plus spécialisé, ont cherché à préciser cette notion. Outre le missel destiné à normaliser le rite, d'autres livres ont souvent pris le nom de Cérémonial. Ils ont été rédigés par des clercs dans un but ecclésiologique à l'usage des prêtres en fonction dans les paroisses. Nombreux au XIX ${ }^{\mathrm{e}}$ siècle, diverses sources y sont compilées et explicitées afin de faciliter les pratiques quotidiennes tout en respectant l'orthodoxie des rites. À Moulins, le vicaire général Adrien de Conny (1817-1891) s'est acquitté de cette tâche en publiant, en 1854 un Petit cérémonial romain rédigé d'après les sources authentiques ${ }^{7}$. D'autres ouvrages sont issus d'une démarche similaire concentrée sur un domaine particulier de la liturgie. À la fin du siècle, par exemple, Xavier Barbier de Montault s'attache à expliquer les usages du costume dans un guide paru en deux tomes intitulé Le costume et les usages ecclésiastiques selon la tradition 
romaine $e^{8}$. Aujourd'hui, à des fins plus scientifiques qu'ecclésiologiques, tout en puisant dans l'ensemble des publications antérieures, il a été établi pour le Thésaurus des objets religieux du culte catholique, de la manière la plus synthétique possible, qu'un ornement est « un ensemble de vêtements et de linges liturgiques assortis et de même couleur, comportant le plus généralement une chasuble, une étole, un manipule, un voile de calice et une bourse de corporal, auxquels s'ajoutent éventuellement des chapes, des dalmatiques parfois un voile huméral, un parement d'autel, etc. »9.

7 En complément de cette définition, une hiérarchie relative à l'utilisation de ces pièces peut être envisagée. Ainsi, la chasuble, la chape ou pluvial et la dalmatique sont des vêtements; l'étole, le manipule, le voile huméral ajoutés à ces vêtements et reflétant la dignité de celui qui les porte sans avoir la fonction proprement dite de vêtir sont des insignes; enfin le voile de calice, la bourse et le devant d'autel ou antependium sont des parements. Il existe également d'autres parements très présents dans les sacristies : pale, pavillon, voile d'exposition, conopée ou voile de tabernacle, pentes de dais.

Même si les versions sont variables d'un auteur à l'autre, la plupart s'accordent à dire que l'origine des vêtements liturgiques de l'Église chrétienne remonte aux premiers siècles de notre ère. À l'époque, dans l'Empire romain, les ministres du culte ne s'habillaient pas différemment des civils. Par contre, si dans la forme et dans la manière de se vêtir, rien ne les distinguait, ces derniers réservaient à l'usage rituel une tenue propre dont la qualité de la matière était supérieure. Ainsi, lorsque les goûts vestimentaires évoluèrent, notamment à partir de la chute de l'Empire romain qui favorisa un important brassage des populations et des cultures, l'Église conserva le costume traditionnel doté désormais d'une dignité particulière. La chasuble, considérée comme le plus essentiel des vêtements liturgiques portés par le prêtre officiant à l'autel ${ }^{10}$, serait issue de la casula ou paenula, sorte de grand manteau d'une seule pièce percé d'un trou pour passer la tête ${ }^{11}$. La dalmatique, tunique ample portée par le diacre était connue à Rome dès l'époque républicaine ; elle était originaire de la région éponyme, la Dalmatie ${ }^{12}$.

Progressivement, une signification symbolique a été adjointe à chacun des vêtements par les auteurs chrétiens du Moyen Âge et a parfois été relayée dans la formulation de prières récitées par les officiants ; la chasuble représente à la fois la charité, la perfection dont doit faire preuve celui qui la porte et le poids du joug du seigneur que la grâce rend léger ${ }^{13}$. Pour le pluvial, long manteau dont la forme et l'usage se fixent à la fin du Moyen Âge ${ }^{14}$, on est proche de l'allégorie car il est considéré comme le symbole de la persévérance, parce qu'ils descend jusqu'aux pieds, de joie suprême, à cause de son chaperon, qui est une pièce d'étoffe plate plus ou moins arrondie et cousue dans le dos à l'emplacement de ce qui était auparavant la capuche, et d'immortalité glorieuse en raison de sa robe ${ }^{15}$. Dans l'usage français, le terme pluvial est remplacé par le mot chape qui désigne à lui seul plusieurs vêtements, ce qui peut être source de confusion. Dans les inventaires officiels et autres règlements, y compris à Moulins, on emploie "chape", parfois orthographiée « chappe » systématiquement à la place de la dénomination exacte.

L'étole, longue bande d'étoffe de 2,50 mètres élargie aux extrémités portée par l'ensemble de la hiérarchie ecclésiastique ${ }^{16}$ serait, suivant le même processus que la chasuble, le vestige d'une robe antique portant le nom de stola. Ayant subi une réduction extrême, elle n'est plus un vêtement mais un insigne. Si son usage est commun, il n'en demeure pas moins que celle-ci se porte différemment suivant le degré atteint au sein de la hiérarchie. L'évêque la laisse pendante sur la poitrine, le prêtre la croise devant en la retenant avec le cordon et le diacre la passe en travers (fig. $\left.\mathbf{n}^{\circ} \mathbf{1}\right)$. Symbole d'innocence et d'immortalité, 
elle signifie que «le prêtre doit être humble et doux». Par sa longueur, elle indique encore «la persévérance que le ministre de Dieu doit avoir en toutes circonstances dans ses œuvres et dans ses actes ${ }^{17}$. Il existe plusieurs types d'étole suivant l'usage qui doit en être fait. L'étole pastorale est plus grande et plus ornée car elle est employée lorsqu'elle n'est pas cachée par un autre vêtement, contrairement à l'étole simple dissimulée sous la chasuble ou la dalmatique. L'étole d'administration est réversible et présente deux couleurs : le blanc et le violet; elle sert, comme son nom l'indique à administrer certains sacrements comme le baptême et évite à l'officiant de s'encombrer de deux étoles ${ }^{18}$. Le manipule, reprend la forme de l'étole dans des proportions moindres. Loin de sa forme et de sa fonction originelle, l'évêque, le prêtre et le sous-diacre le portait au bras gauche (fig. $\mathbf{n}^{\circ}$ 2). Pour les auteurs, il est tantôt dérivé d'une petite nappe, mappa en latin, tantôt d'un mouchoir destiné à essuyer la sueur, nommé sudarium ${ }^{19}$. Son nom actuel est sans doute à rattacher à la signification symbolique dont il s'est chargé : manipulus désigne la gerbe de blé, image du dur labeur et des sacrifices nécessaires à l'obtention du Salut.

Figure 1

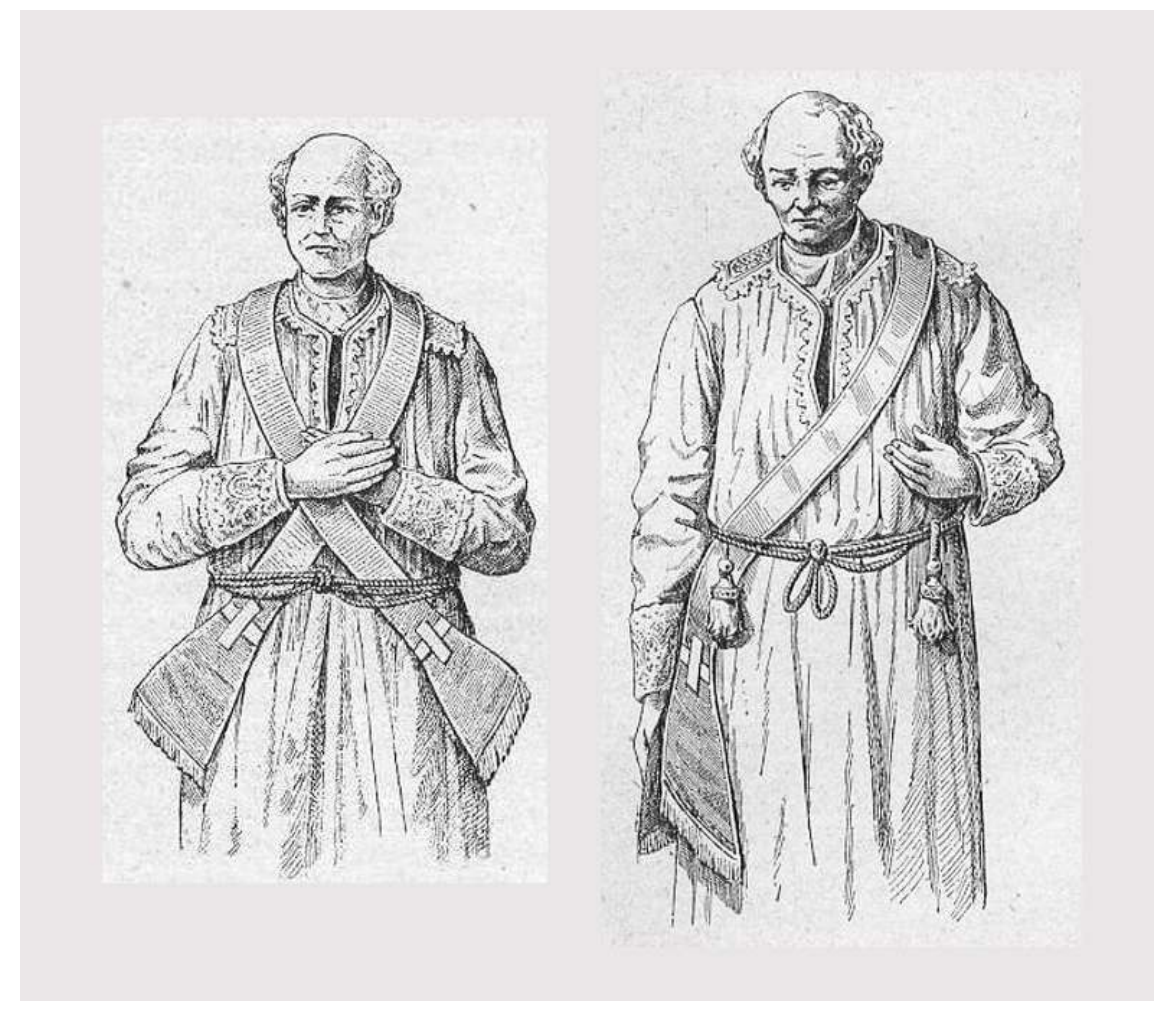

Étole portée par le prêtre (à gauche), par le diacre (à droite), dessins publiés dans Barbier de Montault X., LE COSTUME et LES USAgES ECCLÉSIASTIQUeS SELON LA TRADITION ROMAINE, Tome 2, Paris : Letouzey et Ané, 1899, p. 98-99

Repro. Aurore Chatard. (c) Aurore Chatard 


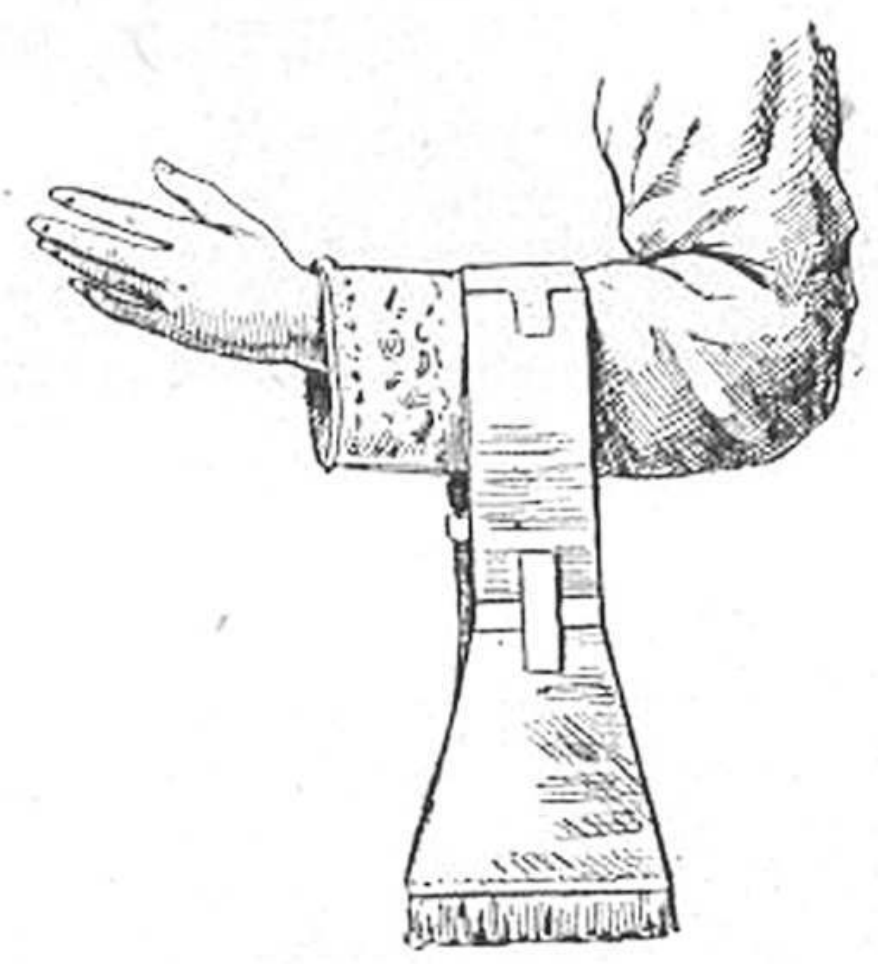

Manière de porter le manipule, dessin publié dans Barbier de Montault X., LE COSTUME ET LES USAgES ECCLÉsiastiques Selon LA tRAdition Romaine, Tome 2, Paris : Letouzey et Ané, 1899, p. 164

Repro. Aurore Chatard. (C) Aurore Chatard

11 Les parements quant à eux ont une destination, comme leur nom l'indique, un peu plus fonctionnelle. Ils servent à couvrir certains objets de la liturgie voire très souvent aussi à les dissimuler complètement. La religion chrétienne étant une religion basée sur le mystère, ces différentes pièces de tissu contribuent à créer des effets particuliers en cachant ou en réservant des objets rituels au cours des différentes célébrations. Le voile de calice recouvre ainsi ce dernier «depuis le commencement de la messe jusqu'à l'offertoire et depuis les ablutions jusqu'à la fin $»^{20}$. Le ciboire est aussi revêtu d'une pièce de tissu nommée pavillon lorsqu'il contient des hosties consacrées (fig. $\mathbf{n}^{\circ} \mathbf{3}$ ). Il sert alors de réserve. On le place dans le tabernacle prévu à cet effet que l'on recouvre lui-même dans ce cas d'un autre voile appelé conopée. L'acte de dissimuler doit être également compris comme une mise à distance destinée à provoquer un sentiment de respect chez le fidèle. Le voile d'exposition (fig. $\mathbf{n}^{\circ} \mathbf{4}$ ) sert à ôter de ses yeux le saint sacrement aux moments où son attention est centrée vers autre chose comme la prédication ${ }^{21}$. 
Figure 3

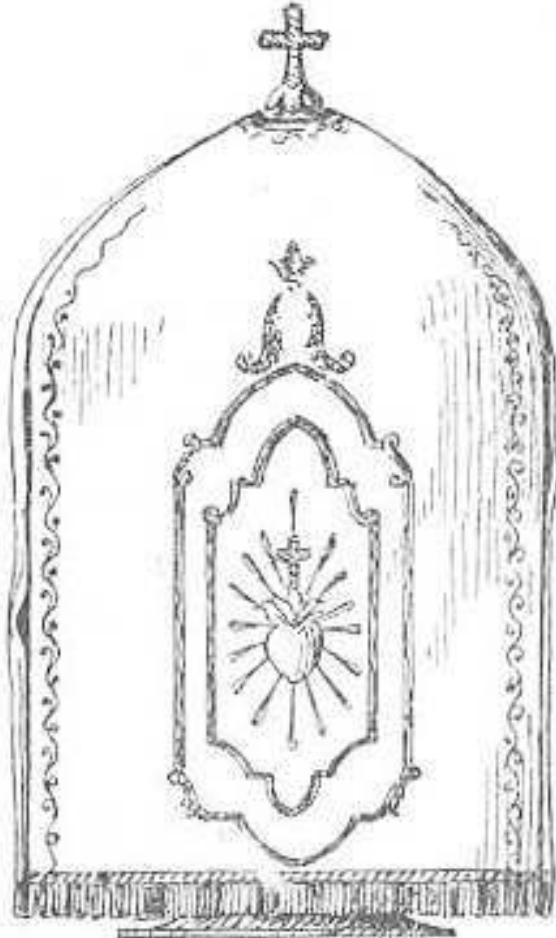

Ciboire recouvert d'un pavillon, dessin publié par Roulin É., LINgES, INSIgNES ET VÊTEMENTS LITURgIQUES, Paris, P. Lethielleux, 1930, p. 183

Repro. Aurore Chatard. (C) Aurore Chatard 
Figure 4

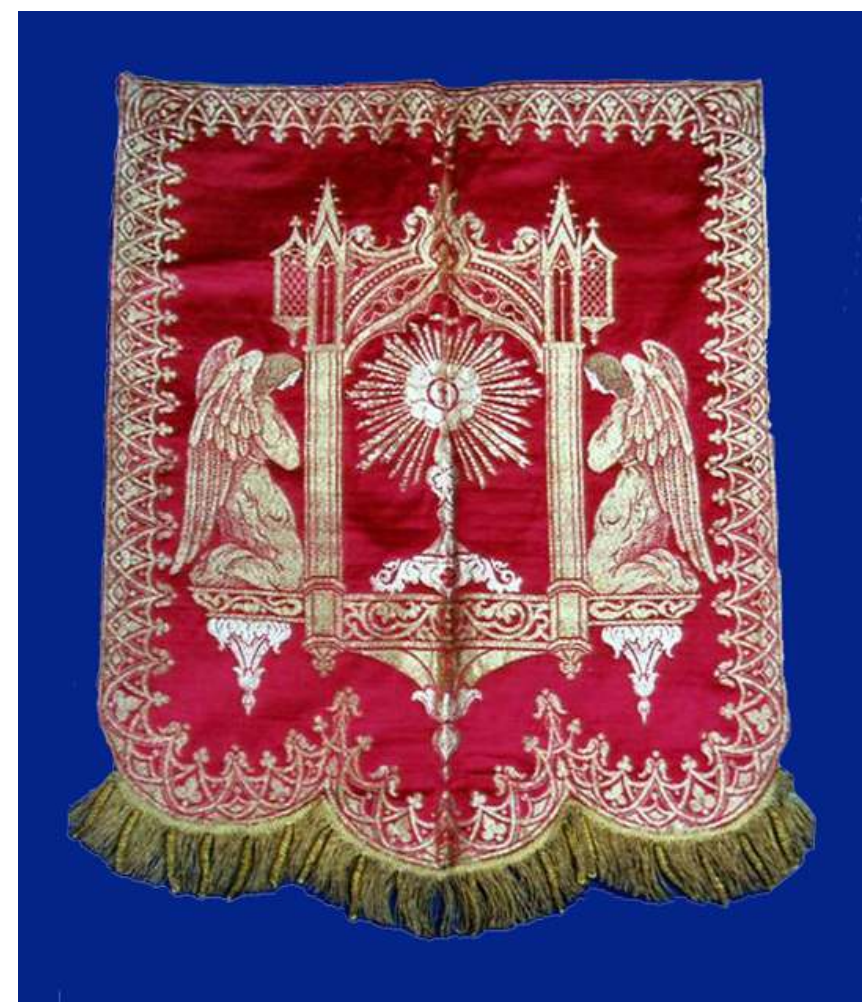

Voile d'exposition, seconde moitié du XIX' siècle, Creuzier-le-Neuf Aurore Chatard, 2001. (c) Aurore Chatard

La plupart du temps, les ornements liturgiques forment des ensembles cohérents tant dans leurs matériaux que dans leurs couleurs. Une fois de plus, loin d'être le résultat du hasard ou la recherche d'un simple agrément esthétique, les couleurs et les matières sont porteuses de multiples significations.

\section{La symbolique des couleurs et le rôle des matières}

Il semblerait que l'utilisation de la couleur se serait codifiée plusieurs siècles après les vêtements. Michel Pastoureau, à l'occasion de ses travaux sur le Moyen Âge, a pu souligner l'importance de celle-ci dans les pratiques religieuses : « La couleur [...] articule l'espace et le temps, distingue les acteurs et les lieux, exprime les tensions, les rythmes, les accents. Sans couleur, pas de théâtralité, pas de liturgie, pas de culte ${ }^{22}$.»

14 Une fois encore, l'usage a précédé la règle. Les premiers traités attribuant une symbolique aux couleurs remontent au IX ${ }^{\mathrm{e}}$ siècle. Au XII ${ }^{\mathrm{e}}$ siècle, de nouveaux écrits viennent attester l'association d'une couleur à une fête ou à un moment particulier du calendrier. Leur nombre se limite à quatre: «le blanc pour les offices des confesseurs et des vierges; le rouge pour ceux des martyrs et des apôtres; le vert pour les dimanches et les féries; le noir pour les jours de deuil ${ }^{23}$. $\gg P a r$ la suite, deux auteurs contribuent durablement à fixer les us et coutumes. Il s'agit du cardinal Lothaire, futur pape Innocent III (1160-1216) qui en 1195 décrit les usages de son diocèse de Rome dans un traité sur la messe intitulé $D e$ sacro sancti altaris mysterio ${ }^{24}$. La diffusion de ce texte pose la liturgie romaine comme celle qui doit être suivie partout et entraîne une vague unificatrice. Le second écrit fondateur, 
le Rationale divinorum officiorum ${ }^{25}$, est celui de Guillaume Durand, évêque de Mende, vers 1285-1286. Il reprend le blanc, le rouge, le noir et le vert cités par Lothaire et y ajoute le violet qui remplace le noir pour les temps de pénitence. Confirmés à l'époque moderne par les prescriptions du concile de Trente, les usages romains comportant l'emploi de cinq couleurs liturgiques principales, auxquelles on peut adjoindre le rose, très rarement utilisée ${ }^{26}$, se sont généralisés. Cependant, il a subsisté des pratiques locales tolérées par l'Église. Au XIX siècle, l'abbé Jean-Baptiste Étienne Pascal s'en fait ainsi l'écho: «Une absolue uniformité n'a jamais été, sur ce point, considérée d'une très haute importance. Ce qu'il convient de bien observer, c'est l'uniformité des couleurs dans un même diocèse ${ }^{27}$ ». Ainsi, c'est pour cela que le gris est parfaitement autorisé à la place du violet dans le diocèse de Lyon. Il en va de même pour le bleu qui est une couleur liturgique en Espagne et en Amérique latine alors qu'elle est totalement rejetée ailleurs. Malgré toutes ces prescriptions, il n'est pas rare de découvrir dans les sacristies des ornements dont la couleur n'est pas orthodoxe. Dans le diocèse de Moulins, un ornement jaune a été repéré : cette couleur est proscrite par la liturgie romaine, alors que la tradition française l'intègre parfaitement ${ }^{28}$. Au fil des siècles, l'utilisation d'une autre couleur, si on peut la considérer comme telle, s'est imposée d'elle-même en raison de son caractère précieux : il s'agit de l'or. Il remplace le blanc, le rouge, le vert et même toutes les couleurs selon l'abbé Pascal ${ }^{29}$. Néanmoins, au XIX ${ }^{e}$ siècle, suivant un courant prônant un retour à une liturgie plus authentique, plus proche des origines, l'or est rejeté. Xavier Barbier de Montault indique que ce n'est pas une couleur proprement dite ${ }^{30}$. Un peu plus tôt dans le siècle, l'abbé de Conny rejette ainsi cette habitude : «Cette diversité de couleurs institués par l'Église, disparaît aussi quand on se sert à toutes les fêtes de chasubles de drap d'or. Dans quelques sacristies se trouvaient de riches ornements qui ne représentaient aucune des couleurs liturgiques, et à cause de leur magnificence on en toléra l'usage. De là, plusieurs ont conclu que l'or remplaçait tout, maxime fâcheuse partout, et qui à l'église détruisait une tradition symbolique des plus vénérables ${ }^{31}$. " L'argent a aussi été employé mais seulement pour remplacer le blanc.

Comme la couleur, la matière des ornements liturgiques est soumise à une réglementation dont le champ d'application ne dépasse pas le tissu de fond. La soie est le matériau visiblement le plus employé. Cependant, les liturgistes déplorent le silence des sources habituellement consultées que sont le Missel romain et le Cérémonial des évêques. Leurs interprétations apparaissent comme étant nettement plus subjectives pour le choix des matières que pour l'emploi des couleurs. La dignité véhiculée par l'effet du vêtement porté est le seul critère vraiment retenu. L'abbé de Conny prend ainsi parti : « La rubrique ayant ordonné expressément que le voile de calice serait en étoffe de soie sans rien spécifier pour la matière des ornements, nous croyons que pour ceux-ci, on peut employer toute étoffe suffisamment digne et convenable; et nous voyons en effet, qu'on s'est servi de chasubles de laine et de camelot sans qu'aucun décret les aient prohibés ${ }^{32}$.» Pendant des siècles, seules la soie et la laine, matériau de moindre coût, étaient utilisées. La question du matériau se complexifie au XIX siècle avec l'apparition de multiples innovations techniques permettant le mélange de plusieurs types de fibres ou la création de fibres textiles complètement artificielles. C'est d'ailleurs à cette période qu'une multitude de décrets sont promulgués par la Sacrée Congrégation des Rites. La laine est interdite successivement le 22 septembre 1837, le 18 décembre 1877 et le 15 avril 1880. L'utilisation de la soie est réglementée à partir du 23 mars 1882 pour la confection de la chasuble en particulier. On « tolère pour les églises pauvres les ornements dont la trame est en soie et la chaîne en une autre matière prohibée ${ }^{33}$ ». D'un point de vue technique, 
cette règle peut susciter l'étonnement car la plupart des tissus employés pour la confection du fond des ornements sont à dominante chaîne: gros de Tours, cannelé, cannetillé, satin, etc..., c'est-à-dire que la chaîne domine sur l'endroit du tissu. Au contraire, les lampas correspondraient à cette prescription car la trame domine, mais ce type d'étoffe est plutôt présent dans le décor des orfrois de chasuble, de dalmatique ou de pluvial, moins soumis à la réglementation que le fond. Des préceptes ainsi plus ou moins nettement exprimés à des dates précises pourraient inciter le chercheur à penser qu'il peut, en l'absence de tout document d'archive, avancer une hypothèse de datation en observant simplement les matériaux des ornements soumis à son examen. La reprise et la répétition de règles déjà établies par les décrets et relayées par la plupart des liturgistes montrent que les pratiques divergent souvent à partir du cadre établi.

Figure 5

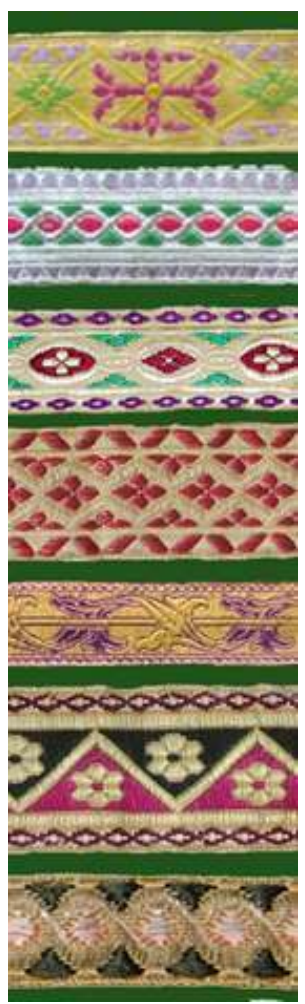

Exemple de galons de soie polychromes

Aurore Chatard, 2001-2005. (c) Aurore Chatard

Sur les ornements liturgiques, le tissu de fond est généralement agrémenté de passementerie se présentant sous la forme de galons de plusieurs largeurs dont la fonction est d'abord structurante avant d'être décorative. Sur les vêtements : chasuble, pluvial et dalmatique, les galons forment les orfrois. En l'absence d'un quelconque décor, ils sont les seuls éléments permettant de les distinguer. Sur le pourtour des vêtements, un galon le plus souvent étroit, mais pas toujours, souligne la forme générale du vêtement et aussi le col pour la chasuble si elle en possède un. Il peut être droit ou festonné vers l'extérieur. Sur les insignes et les parements, il est également utilisé pour souligner le pourtour. Pour l'étole et le manipule, il sert à former les croix situées au milieu et sur les palettes aux extrémités. Le voile et la bourse reçoivent également une croix. En matière de galon, selon les réflexions de Barbier de Montault, on peut supposer qu'il existe des 
« modes » nationales : « à Rome, [les galons] sont constamment en or ou en soie jaune. [...] Le galon blanc si populaire en France y est absolument inconnu même sur le violet et le noir ${ }^{34}$. » Jusqu'au XIX ${ }^{\mathrm{e}}$ siècle, en France, les passementeries religieuses de soie blanche ou jaune remplacée parfois par du métal doré ou argenté sont effectivement parmi les plus courantes. Le galon métallique destiné à la liturgie est spécifique : on le nomme galon système. Il a la particularité d'avoir un envers textile qui présente à la fois l'avantage de garder une certaine souplesse au vêtement et celui d'être plus économique. À la place de ce type de galon, on rencontre parfois une sorte de dentelle également tissée de fil doré ou argenté. Il faut préférer le terme de crépine pour la désigner. Elle joue le même rôle décoratif et structurant que le galon. À partir de la seconde moitié du XIXe siècle, le choix en matière de passementerie a été sensiblement élargi pour répondre à une nouvelle tendance du pour le Moyen Âge . Les galons de soie deviennent polychromes, associant des tons variés et soutenus présents dans l'art de cette époque : rouge, bleu, vert, etc. sans pour autant être de fidèles restitutions (fig. $\mathbf{n}^{\circ} 5$ ).

La confection d'ornements liturgiques semble être un carcan pour l'artisan-créateur qui doit le plus possible s'astreindre aux formes préétablies et à toutes les directives précédemment évoquées. Toutefois, il lui reste de larges possibilités de laisser libre cours ou presque à son imagination dans l'apposition de multiples décors.

\section{Le décor}

18 Les ornements liturgiques sont très souvent rehaussés d'un décor composé de tissus, de broderie, de passementerie ou encore de peinture. Pour les vêtements, le décor se concentre sur des bandes appelées orfrois et aussi sur le chaperon pour le pluvial. Moins soumis à la norme, il a subi un peu plus les caprices de la mode et reflète davantage le goût de l'époque. La manière la plus simple et aussi parmi les plus économiques d'apposer une ornementation est d'utiliser une étoffe différente de celle du fond. Les étoffes brochées et les lampas aux motifs riches et variés sont alors privilégiés. Cette méthode est largement répandue au XVIII siècle avec l'emploi de soieries polychromes à décors profanes $^{35}$. Elle se perpétue au siècle suivant. Cependant, les tissus profanes sont écartés ou retravaillés afin d'acquérir une spécificité liturgique. Les symboles religieux prennent une place grandissante et les tissus fleuris pourvus d'une large gamme de tons sont volontiers reteints pour répondre à la règle des couleurs.

Utilisée depuis plus longtemps pour les ornements liturgiques, la broderie est le moyen le plus courant pour enrichir un décor. Dès le Moyen Âge, on exécute de véritables scènes représentant des cycles illustrés tirés de la Bible et de textes apocryphes: Passion, vie de la Vierge, vie de saints, etc. à l'image de la chape de Saint-Bertrand-de-Comminges datant du premier quart du $\mathrm{XIV}^{\mathrm{e}}$ siècle ${ }^{36}$. Au XVII ${ }^{\mathrm{e}}$ siècle, avec l'apparition du goût pour de nouvelles variétés de fleurs, on substitue à ces scènes des décors végétaux désormais plus appréciés ${ }^{37}$. Au siècle suivant, la broderie tend à disparaître des ornements liturgiques. Certains en sont totalement dépourvus: les riches soieries aux motifs polychromes se suffisent à elles-mêmes. La mode des tissus unis ou rayés à la fin du XVIII ${ }^{e}$ siècle s'accompagne d'un retour d'abord discret de la broderie. Cette technique est en réalité une mosaïque de techniques. Les plus courantes au XIX ${ }^{e}$ siècle sont recensées par Thérèse de Dillmont dans un ouvrage pratique à destination commerciale publié pour la première fois en 1886 par la firme D.M.C. et intitulé : Encyclopédie des ouvrages de dames ${ }^{38}$. On y 
retrouve ainsi l'exécution largement détaillée des points de broderie sur soie et velours, de la broderie d'or, de la broderie-application et de la tapisserie.

Tout au long du siècle, la broderie reste cependant très concurrencée par une innovation appelée tissage « à la disposition » ou tissage « en forme » dont le prix de revient est plus abordable. Le décor est tissé directement dans le tissu suivant une forme déterminée au préalable. Les orfrois sont très fréquemment confectionnés ains ${ }^{39}$. Parfois, des ornements complets sont tissés selon cette méthode: le fond, les galons, les orfrois et la passementerie, y compris les franges, sont inclus dans le décor du tissu (fig. $\mathbf{n}^{\circ} \mathbf{6}, \mathbf{n}^{\circ} \mathbf{7}$ ).

Figure 6

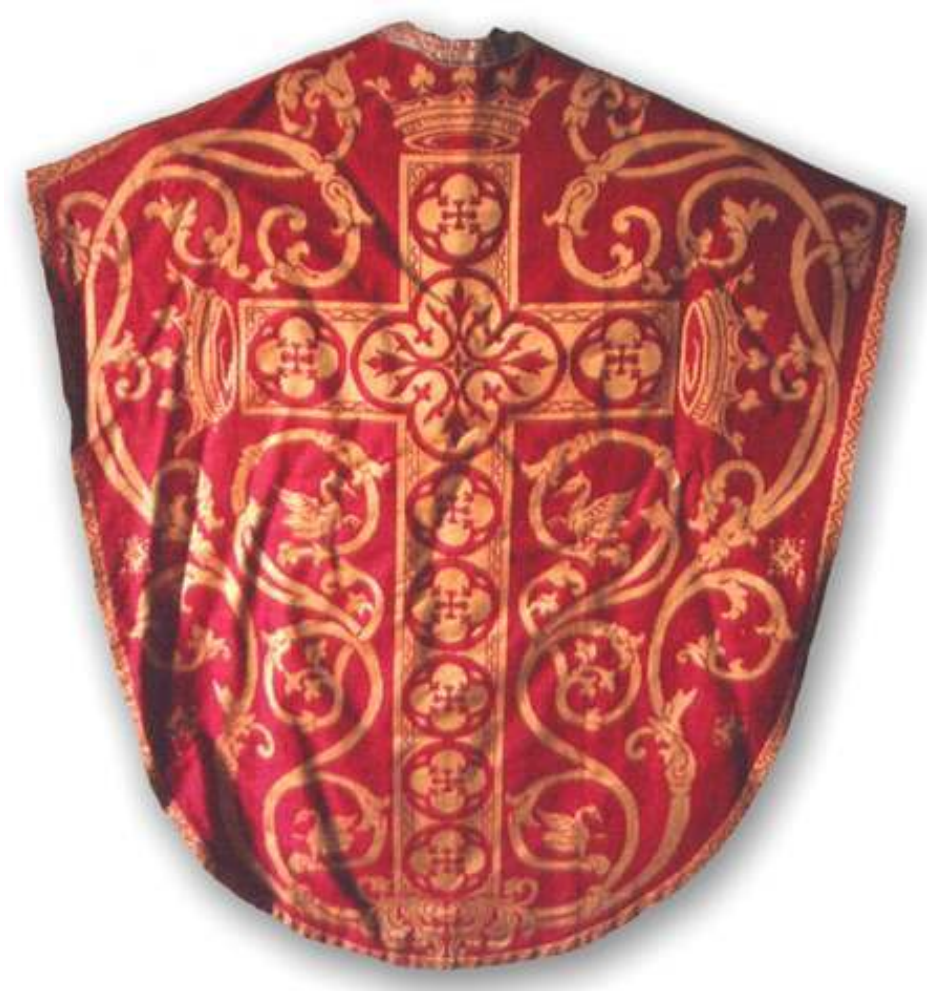

Chasuble tissée à la forme. Le Mayet-d'École

Aurore Chatard, 2002. (c) Aurore Chatard 
Figure 7

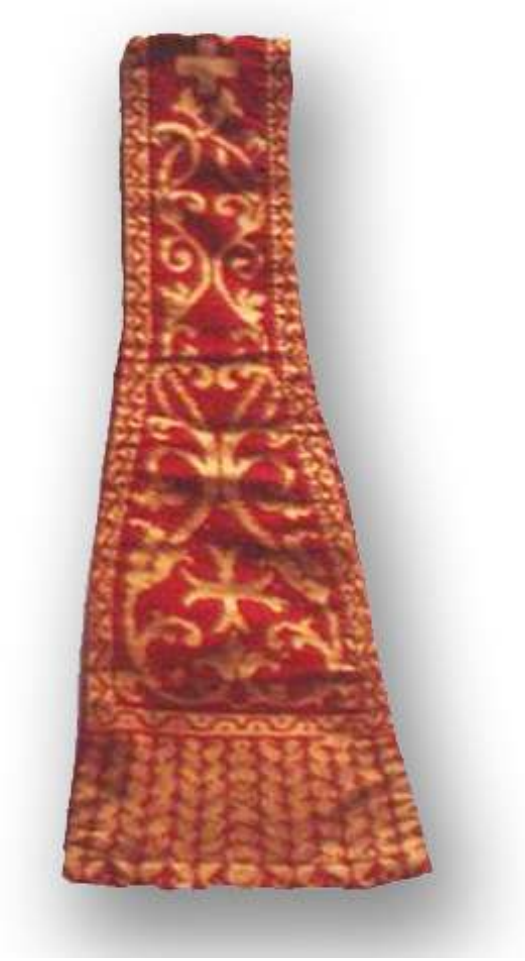

Manipule tissé à la forme. Le Mayet-d'École

Aurore Chatard, 2002. (c) Aurore Chatard

21 Il existe un dernier moyen pour enrichir le fond des ornements liturgiques et rompre la monotonie produite par l'emploi de matériaux simples dont le coût est moindre pour les paroisses modestes : il s'agit de la peinture. En remplacement de la broderie, les éléments du décor sont directement appliqués au pinceau sur le tissu (fig. $\mathbf{n}^{\circ} \mathbf{8}$ ). 


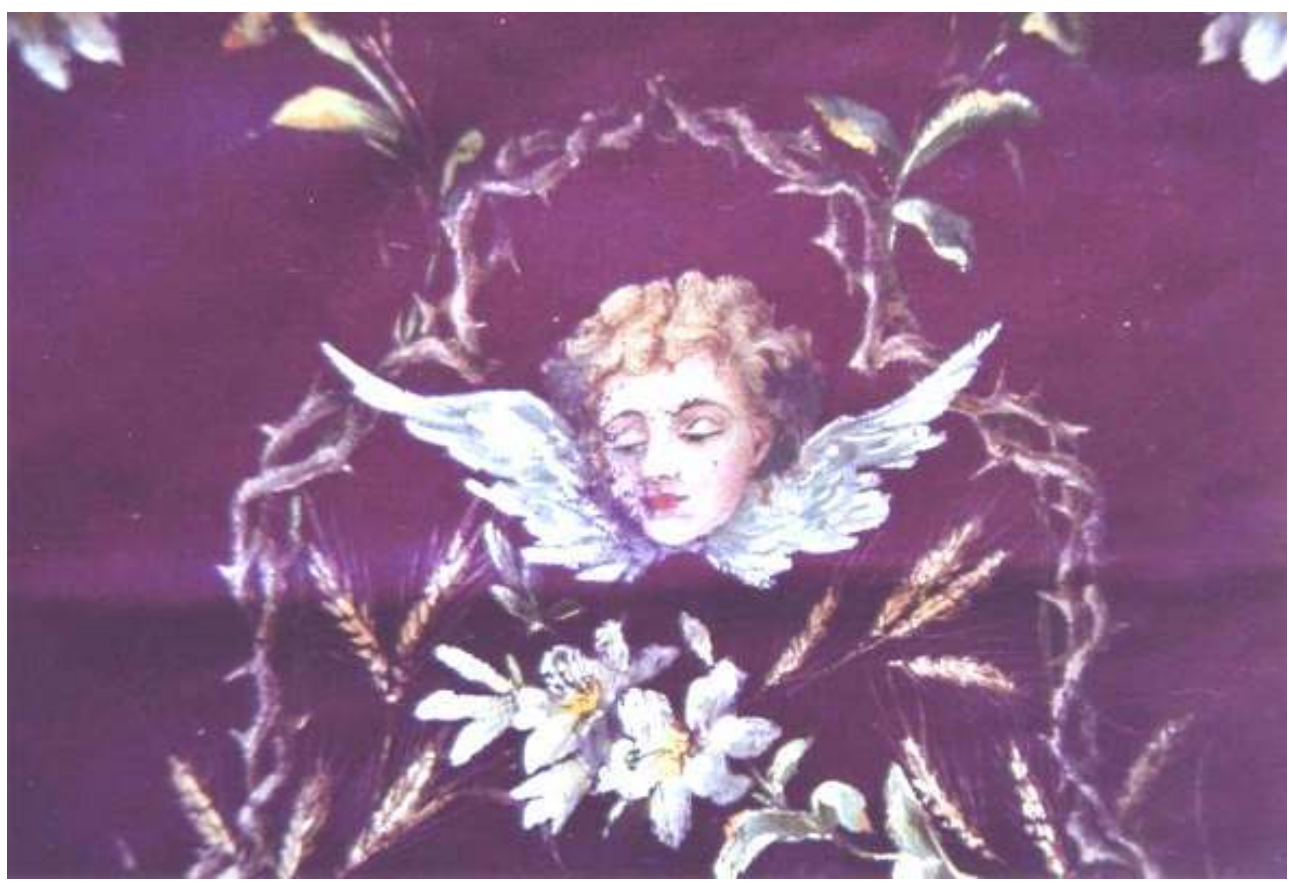

Chasuble peinte, détail. Ébreuil

Aurore Chatard, 2003. (c) Aurore Chatard

$\mathrm{Au} \mathrm{XIX}^{\mathrm{e}}$ siècle, la multiplicité des techniques employées à la création textile et notamment aux ornements liturgiques témoigne d'un savoir-faire élaboré destiné aussi à répondre à des nécessités économiques et commerciales.

\section{Acquisition des ornements liturgiques}

L'acquisition et l'entretien des ornements liturgiques représentent une charge réelle pour la paroisse. Au XIX ${ }^{e}$ siècle, la plupart d'entre elles, particulièrement dans le département de l'Allier, se retrouvent dans un certain dénuement dont la principale cause est la réquisition et la vente des biens du clergé à l'époque révolutionnaire. La volonté de l'Église de redonner un peu de décence, voire de lustre à la célébration du culte explique cette demande croissante à l'origine d'un développement remarquable du marché de la chasublerie et des articles religieux en tous genres.

\section{La fabrique et les fidèles}

Les fabriques existent au moins depuis le XIII ${ }^{e}$ siècle. Elles réapparaissent après la Révolution dans un des articles organiques ajoutés au Concordat de 1801. Au XIX siècle, deux textes en précisent le règlement: un décret impérial du 30 décembre 1809 et une ordonnance royale du 12 janvier 1825. La fabrique est un conseil dont les membres sont élus par l'assemblée des habitants et qui doit prendre en charge l'administration temporelle des églises paroissiales. Elles sont, de ce fait, tenues de se procurer des ornements. Le maire et le curé siègent à cette assemblée en tant que membres de droit. Ce 
dernier ne dispose donc d'aucun pouvoir de décision en propre ni d'aucune autonomie financière.

Les revenus des fabriques sont de diverses natures. Il y a tout d'abord les produits financiers provenant de dons, de legs ou de fondations de messes. Puis vient ensuite le produit spontané des terrains servant de cimetière. À Creuzier-le-Neuf, par exemple, les fruits des noyers plantés sur les terrains appartenant à la fabrique étaient vendus chaque année ${ }^{40}$. Enfin la plus grande partie des revenus est constituée, en dehors de l'argent déposé dans des troncs, de taxes diverses: prix de la location de chaises et de la concession annuelle des bancs placés dans l'église, quêtes diverses effectuées durant les offices, fraction du casuel revenant à la fabrique, le casuel étant la taxe, déterminée par l'évêque, à verser lors des mariages et des obsèques ${ }^{41}$. Même si, à défaut de fabrique, l'évêque doit fournir les ornements de la cathédrale et le curé ceux de l'église paroissiale, ceux-ci appartiennent en propre à l'église et doivent y rester. En aucun cas, les églises les plus riches ne peuvent prêter leurs biens aux plus pauvres ${ }^{42}$.

Figure 9

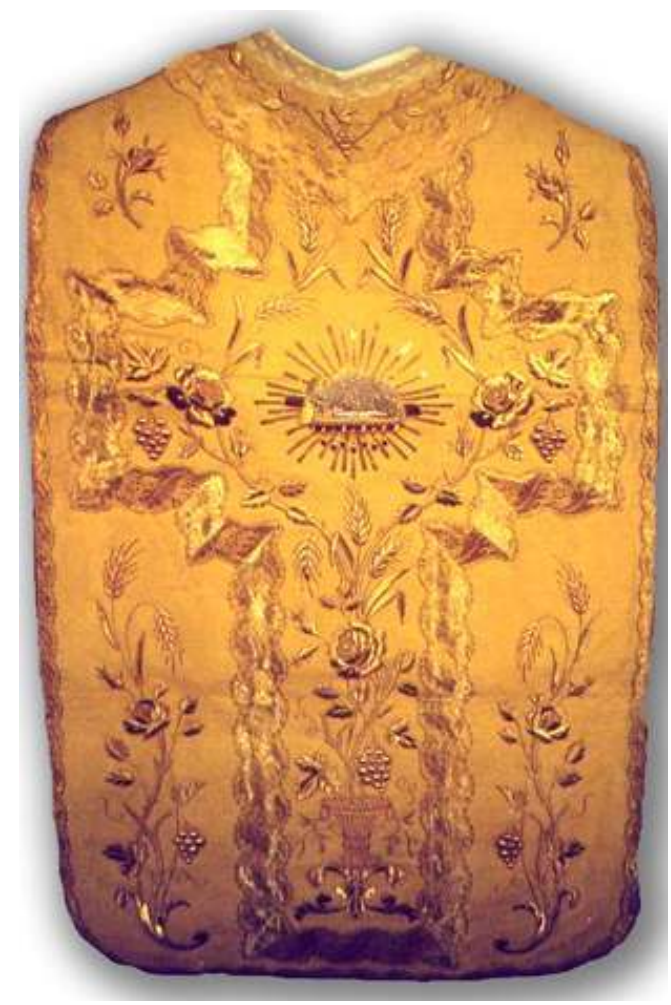

Chasuble de l'ornement supposé avoir été offert par la duchesse de Morny, Ébreuil Aurore Chatard, 2003. (c) Aurore Chatard

Parmi les dons perçus par la fabrique, certains peuvent se présenter en nature. Si un objet nécessaire est manquant, il peut être acheté par un fidèle à titre personnel et donné à l'église. Même si la fabrique régit les biens, on se tourne plus facilement vers le curé qui demeure l'autorité spirituelle afin qu'il serve d'intermédiaire. Il est parfois difficile de savoir quel objet a été offert par les fidèles, car les documents tels que les registres de comptes ne le mentionnent pas. Toutefois, quand le donateur est illustre, le fait a suffisamment d'importance pour être inscrit dans les procès-verbaux d'assemblée générale des conseils de fabrique et ensuite transmis par la tradition orale. Un inventaire 
de 1901 de la paroisse de Chouvigny mentionne «trois [ornements] en drap d'or dont un fort beau, don de la duchesse de Morny ${ }^{43}$ » qui, avec son mari, avait possédé sur le territoire de la commune une demeure construite entre 1855 et 1857 (fig. $\mathbf{n}^{\circ}$ 9). Plus tard, à l'occasion des inventaires de 1905-1906, au moment de l'adoption de la loi sur la Séparation des Églises et de l'État, il est fréquent de retrouver les réclamations des donateurs qui souhaitent récupérer les objets qu'ils ont achetés. Par exemple, à Marcenat, la comtesse d'Arfeuilles en revendique plusieurs, dont un dais, dans un courrier adressé à l'administration daté du 20 mars 1906. Ces démarches sont généralement soutenues par les membres du conseil plutôt méfiants à l'égard des dispositions prises par l'État.

En raison de moyens trop réduits engendrés par une balance des comptes déséquilibrée, les fabriques peuvent tenter d'obtenir une subvention délivrée par les pouvoirs publics. Le premier échelon administratif vers lequel, on se tourne naturellement est la commune. D'après un décret de 1809 , celles-ci doivent subvenir aux dépenses de fonctionnement du culte et à l'entretien des bâtiments en cas de défaillance du côté de la fabrique. À peine plus riches, elles s'acquittent des charges les plus urgentes : l'achat de mobilier est bien souvent une préoccupation de second ordre. Après des travaux lourds, il est presque toujours inenvisageable pour les communes modestes de pourvoir à l'aménagement intérieur des édifices. Ainsi, ces dernières ont encore une possibilité de recours. Depuis la Restauration jusqu'à la loi de Séparation, les différents gouvernements successifs ont souhaité se garantir le soutien de l'Église en allouant un budget distribué par le ministère de la Justice et des Cultes et destiné à la construction, à l'entretien ainsi qu'à l'aménagement des bâtiments ordinairement du ressort des fabriques. Ce genre de démarche semble avoir été relativement fréquent car il n'est pas rare de retrouver, dans la sous-série $5 \mathrm{~V}$ des Archives départementales de l'Allier consacrée à l'administration des fabriques, la mention d'une somme, généralement de deux cent cinquante francs, attribuée pour l'« achat d'objets mobiliers ». Malheureusement, le détail des objets acquis grâce à cette somme est rarement indiqué. On ne peut savoir si des ornements liturgiques figurent au nombre des achats.

De la simple nécessité de rendre un culte décent dans une paroisse pauvre à celle de correspondre à la générosité d'un personnage illustre non dépourvues de ressources, les marchands se doivent de proposer des articles pouvant combler toutes les attentes.

\section{Les marchands}

Les matériaux mis en œuvre dans les ornements liturgiques requièrent une multitude de savoir-faire issus d'une chaîne complexe, à la fois industrielle et artisanale. On peut ainsi remonter jusqu'aux producteurs de soie ou aux fileurs de métal. À leur extrême opposé, celui qui confectionne le produit fini est nommé chasublier. Dans le Dictionnaire des arts liturgiques, un panorama de l'organisation des industries liturgiques est brossé pour la France. $\mathrm{Au} \mathrm{XIX}^{\mathrm{e}}$ siècle, le grand centre de tissage des soieries est Lyon. Tout naturellement, les chasubliers prospèrent dans la ville à proximité des matières premières. Cependant, le rôle de la capitale est primordial dans l'élaboration du goût; des maisons au destin remarquable y sont donc solidement implantées. Certaines d'entre elles ont eu une assez grande longévité pour être à l'origine de véritables dynasties de chasubliers. Biais compte parmi celles-ci : la maison voit le jour en 1782 et, au cours du siècle suivant, occupe plusieurs étages d'un immeuble en vue sur la place Saint-Sulpice à Paris (fig. $\mathbf{n}^{\circ} \mathbf{1 0}, \mathbf{n}^{\circ} \mathbf{1 1}$ ). Biais a même réussi, comme certaines autres grandes entreprises, 
à maîtriser toute la chaîne de production du tissage à la vente. Pour cela, outre son atelier de confection parisien il a monté sa propre fabrique à Lyon ${ }^{44}$.

Figure 10

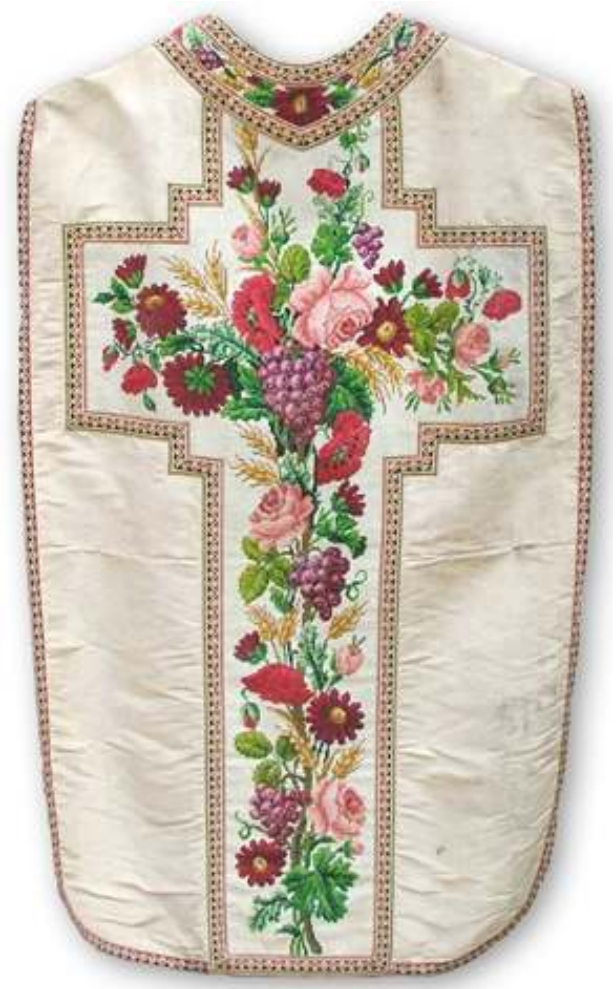

Chasuble d'un ornement confectionné par Biais Aîné fils et Rondelet, Vicq Aurore Chatard, 2004. (c) Aurore Chatard 


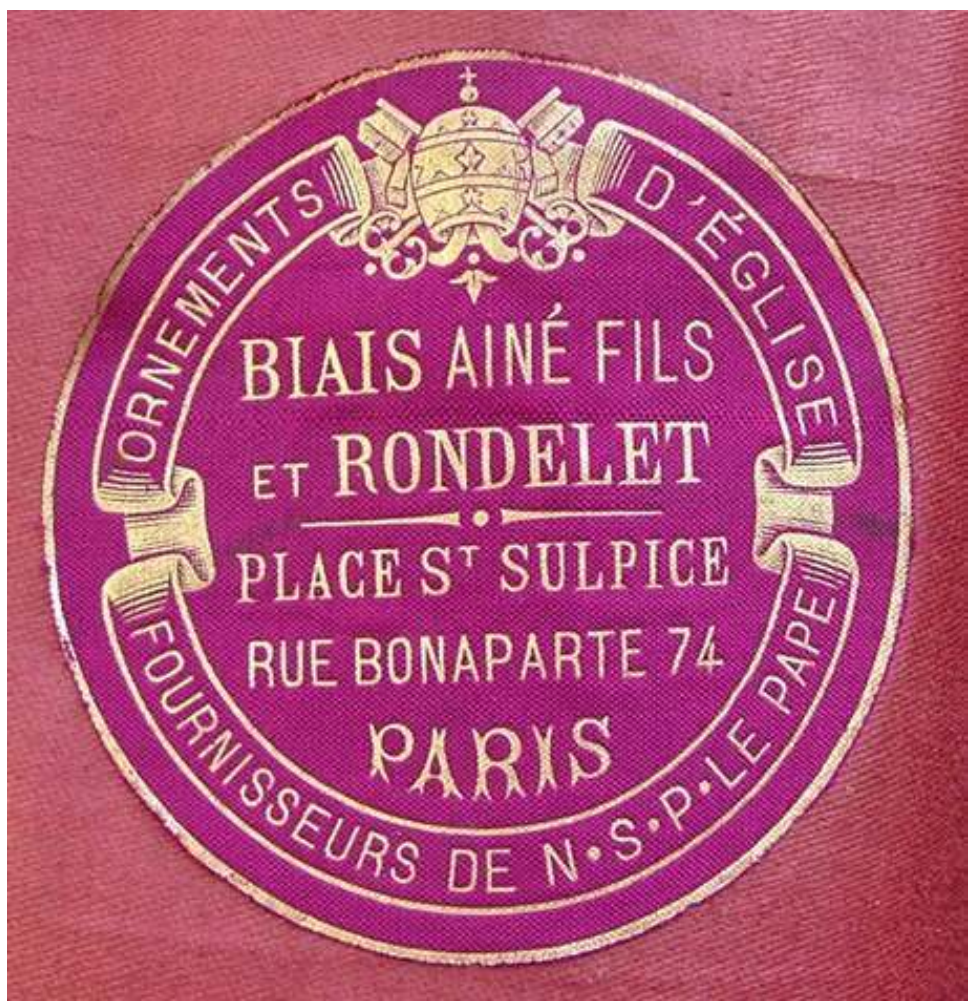

Étiquette du fabricant fixée sur la doublure de chasuble, Vicq Aurore Chatard, 2004. (c) Aurore Chatard

Un des atouts majeurs de ces entreprises prospères réside dans leur capacité à communiquer et à atteindre le client, même dans les endroits les plus reculés. En effet, au XIXe siècle, les catalogues de vente d'objets religieux apparaissent et se multiplient ${ }^{45}$. Ils permettent aux acheteurs potentiels de choisir les articles à distance et d'acheter par correspondance. Cette nouvelle habitude se généralise grâce au quadrillage progressif du territoire par le chemin de fer. En 1862, le trésorier de la fabrique de Creuzier-le-Neuf inscrit à son registre " payé à la gare de St-Germain [-des-Fossés] pour le port de la crèche et d'une chasuble venues de Paris » la somme de six francs et trente centimes ${ }^{46}$ (fig. $\mathbf{n}$ -12). 


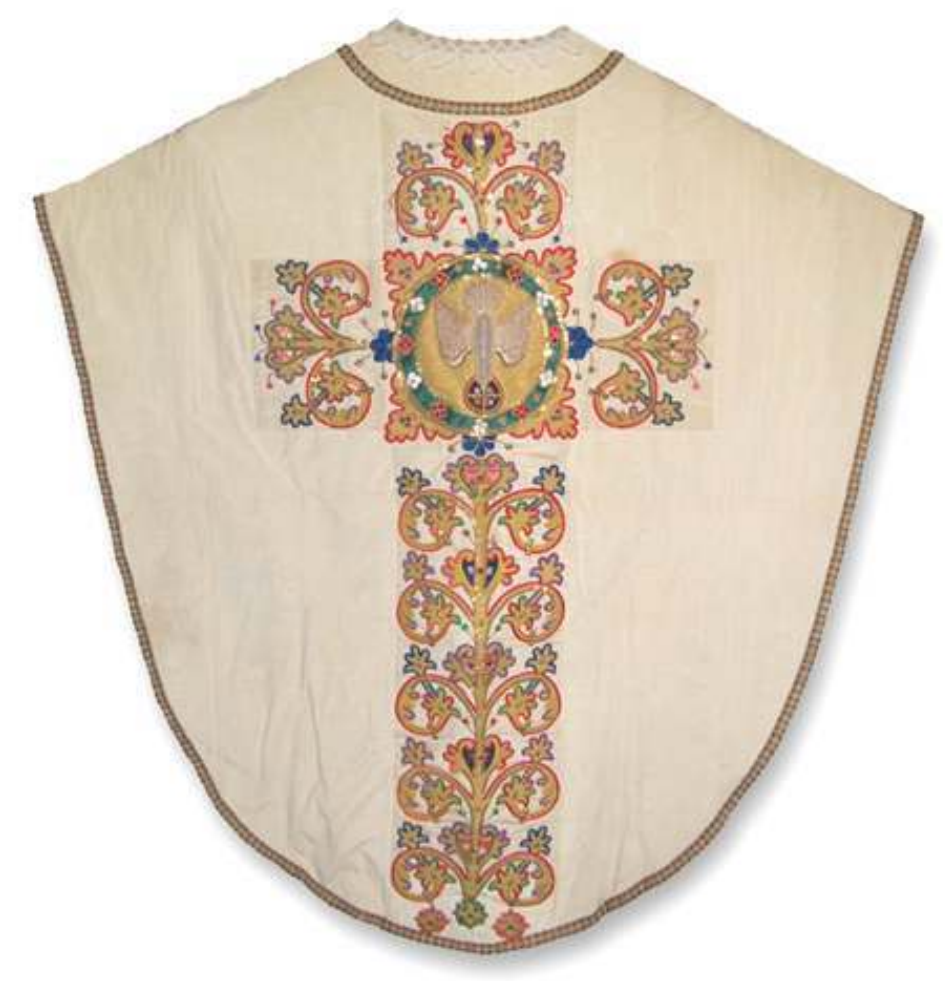

Chasuble de forme semi-gothique, Creuzier-le-Neuf

Aurore Chatard, 2001. (c) Aurore Chatard quatre-vingt-douze francs, une bannière de la Maison Léon Bougron située dans le quartier de Montmartre à Paris. De pareils exemples foisonnent. La plupart de ces maisons proposent un choix assez varié. Nous pouvons, de nouveau, citer la Maison Biais dont le catalogue des ornements d'églises de 1900 propose des articles pouvant presque être adaptés à l'infini ; l'acheteur est interpellé ainsi dès les premières pages : « Notre but a été de donner les meilleurs types de chaque genre. Chaque modèle peut en effet être exécuté de diverses manières et à divers prix. Il suffit donc pour nous donner les ordres de nous désigner :

$1 \%$ Quel est l'objet que l'on désire ;

$2^{\circ}$ Quel modèle on choisit ainsi que les modifications qui doivent être apportées ;

$3 \%$ Quels seront son style et sa couleur ;

$4^{\circ}$ / Dans certains cas, quelle sera sa dimension;

$5 \%$ Dans quel prix nous devrons approximativement nous renfermer ;

Ces cinq renseignements nous suffisent; néanmoins nous serons heureux de suivre les recommandations spéciales qui nous seront faites soit pour suivre un usage local, soit pour exécuter un dessin qu'on nous enverra. ${ }^{47}$ » 


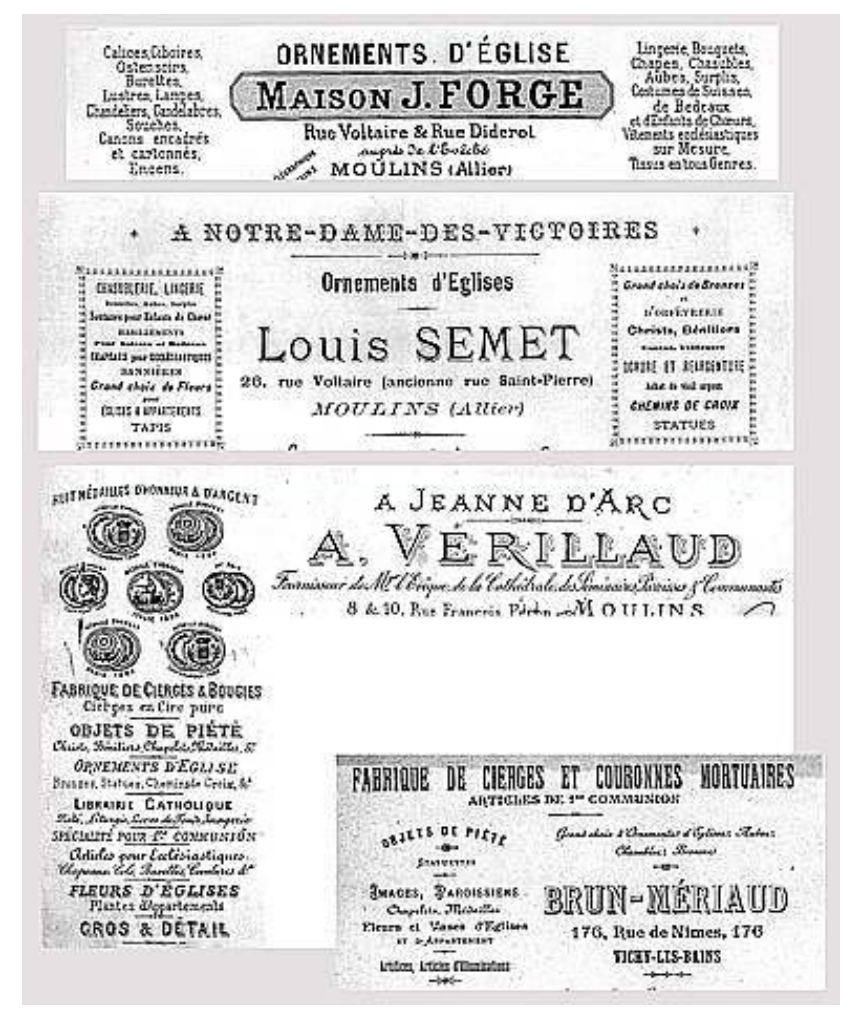

En-têtes de factures des vendeurs d'objets liturgiques implantés dans l'Allier vers 1900 Aurore Chatard, 2001-2005. (c) Aurore Chatard

Compte tenu d'une stratégie commerciale aussi élaborée, on pourrait imaginer que ces grandes maisons répondent à la totalité de la demande dans ce secteur. Il n'en est rien puisque de nombreuses boutiques de taille plus modeste et d'un rayonnement plus limité se multiplient sur le territoire. Celles-ci n'ont pas de spécialité particulière et proposent à la vente tout le " nécessaire " pour l'exercice du culte. Souvent, il s'agit simplement d'un revendeur et non d'un fabricant ${ }^{48}$. Dans la ville épiscopale de Moulins, vers 1900, pas moins de trois commerces sont en concurrence : J. Forge, Louis Semet et A. Vérillaud (fig. $\mathbf{n}^{\circ}$ 13). À environ cinquante kilomètres de là, la maison Brun-Mériaud est installée à Vichy, la deuxième ville du département.

Traditionnellement sous l'Ancien Régime, certains ordres religieux féminins avaient fait de la confection d'ornements liturgiques et de linges pour l'autel leur activité principale. $\mathrm{Au}$ fur et à mesure de leur réimplantation au $\mathrm{XIX}^{\mathrm{e}}$ siècle, ceux-ci renouent avec leur savoir-faire et parfois même se constituent en société commerciale. À Moulins, sans toutefois aller jusque-là, le Carmel fraîchement réinstallé dans la ville se voit confier par l'évêque l'entretien des ornements, des linges et la fabrication des hosties pour la cathédrale. Et, sans doute pour améliorer leurs revenus encore faibles, il annonce, par une lettre aux curés du 23 mars 1853, que désormais les religieuses «s'occupent de la confection des ornements, et mettent à la disposition des églises du diocèse, le travail le plus soigné et la plus intelligente économie ${ }^{49} »$.

La profusion des offres commerciales s'accompagne, à partir du deuxième quart du XIX siècle, d'un réel questionnement historique et symbolique sur les objets religieux, notamment ceux conservés depuis le Moyen Âge . Le goût pour l'esthétique de cette 
période s'empare de certains clercs qui confèrent aux objets nouvellement créés et répondant aux critères médiévaux une dimension non seulement symbolique d'une liturgie renouvelée, mais aussi politique, rejetant l'image d'une Église gallicane sous tutelle de l'État.

\section{Le renouvellement du vestiaire : entre idéal liturgique et contrainte économique}

41 Le diocèse de Moulins dont l'idée est en germe depuis l'Ancien Régime est officiellement créé en 1822. Son territoire est constitué grâce au démembrement des trois diocèses se partageant précédemment le territoire du département de l'Allier : Clermont, Bourges et Autun. La liturgie adoptée pour cette nouvelle entité par le premier évêque, Antoine de Pons de La Grange (1759-1849), originaire de Clermont, reprend les usages locaux tout en privilégiant ceux du lieu d'où il vient. Tout était à créer sur ce nouveau territoire où les fidèles avaient été pendant plusieurs décennies laissés de côté par une autorité épiscopale souvent trop lointaine.

\section{Pierre-Simon de Dreux-Brézé, évêque de Moulins de 1850 à 1893}

Figure 14

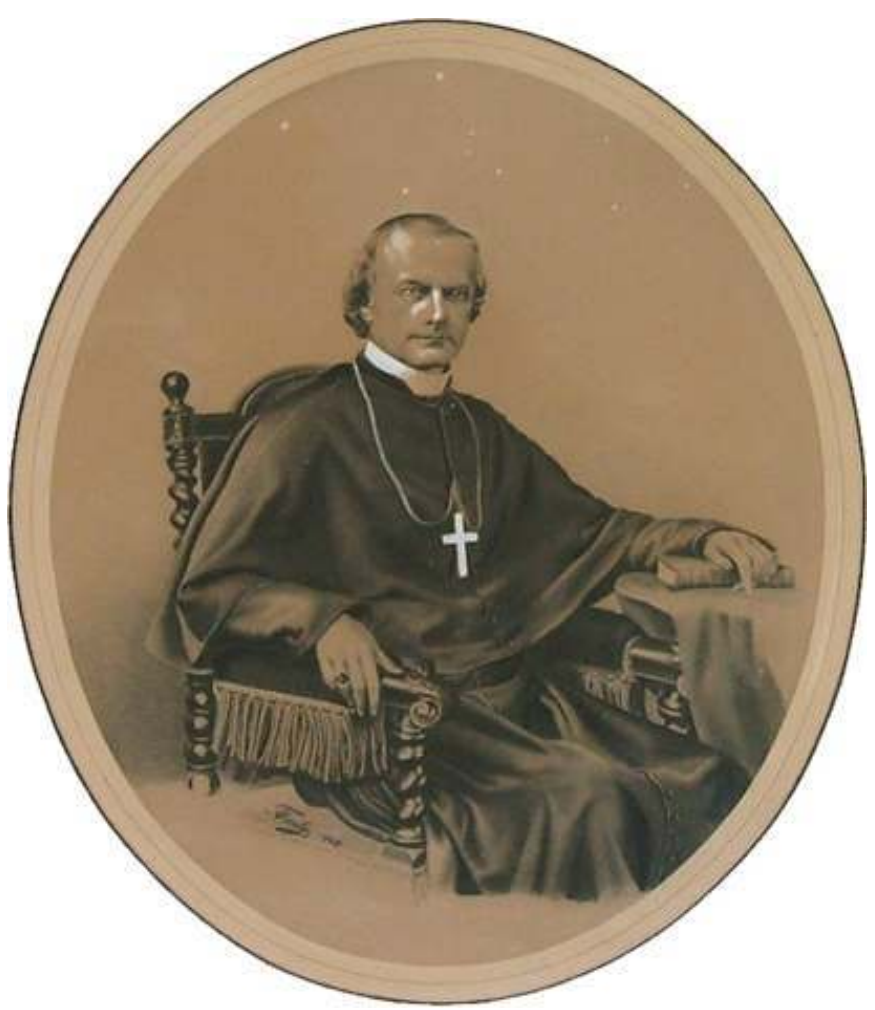

Mouly, portrait de Pierre-Simon de Dreux-Brézé, dessin, 1868, Évêché de Moulins Aurore Chatard, 2005. (c) Aurore Chatard

Pierre-Simon de Dreux-Brézé (1811-1893), troisième fils du marquis de Dreux-Brézé, maître des cérémonies de Louis XVI, débute une carrière ecclésiastique prometteuse à Paris. Le 28 octobre 1849, il est nommé évêque et entre à Moulins le 30 avril suivant (fig. 
$\mathbf{n}^{\circ}$ 14). Sur bien des points, il reprend l'ouvrage de son prédécesseur. Il reconnaît très volontiers l'ampleur de la tâche accomplie par celui-ci. Cependant dès son arrivée, un vent de changement souffle sur le diocèse. Dès les années 1840 , naît et croit au sein de l'épiscopat français une nouvelle tendance ultramontaine caractérisée par une volonté de dépendre directement du Saint-Siège sans intervention intermédiaire de la part de l'État. Cette idée s'oppose directement à celle d'une Église de France et du courant gallican en vigueur depuis l'Ancien Régime. Mgr de Dreux-Brézé est l'un des instigateurs de ce mouvement avec une poignée d'autres évêques dont Mgr Pie, de Poitiers, avec qui il entretient une relation assez étroite. La première réforme répondant à ce nouvel idéal intervient à Moulins dès 1853 : une liturgie conforme au modèle romain est adoptée. Elle s'appuie sur le Missel romain, un propre diocésain rédigé par Dom Guéranger de Solesmes en personne, qui est une autre cheville ouvrière de l'ultramontanisme en France, et d'un catéchisme. En 1854, Adrien de Conny, vicaire général, publie en complément le Petit cérémonial romain rédigé d'après les sources authentiques ${ }^{50}$ déjà cité plus haut. Issu du même groupe de prêtres ultramontains de Paris, il accompagne Mgr de Dreux-Brézé en Bourbonnais lors de sa nomination et y retrouve ses racines. Partageant les mêmes idées que ce dernier, il participe très activement à la rénovation liturgique du diocèse. Il écrit beaucoup et se retrouve à la tête de la commission diocésaine destinée à régler tous les détails de la mise en place des nouveaux usages.

Dès le début de son épiscopat, Mgr de Dreux-Brézé a su affirmer fermement ses positions. En premier lieu, il demande que la cérémonie de son ordination soit présidée par le nonce, Mgr Fornari, un autre ultramontain notoire, à Notre-Dame de Paris au lieu de Sens qui est la métropole de Moulins. L'archevêque de Paris résiste à la première requête mais cède à la seconde. À la dernière minute, le nouvel évêque de Moulins demande expressément qu'on use du rituel romain. Il réussit ainsi à donner suffisamment de relief et de rayonnement à cet événement qui lui permet d'afficher publiquement et officiellement ses opinions. Sous le Second Empire, l'ultramontanisme occupe une place minoritaire au sein de l'épiscopat français. L'évêque de Moulins montre un esprit frondeur en s'opposant régulièrement au gouvernement. Dans le domaine des arts, son orientation politique se traduit par son attachement au mouvement archéologique. Il soutient la mise en pratique dans son diocèse de cette nouvelle esthétique. Il suit de très près le chantier d'agrandissement de la collégiale de Moulins, devenue cathédrale entre 1852 et $1876^{51}$. Les métiers d'art ne sont pas en reste : la chapelle de son sacre est réalisée par l'orfèvre Poussielgue-Rusand, sur les dessins du Père Arthur Martin dont on ne conserve que le ciboire ${ }^{52}$ Le retour au Moyen Âge est encore marqué par la forme de la chasuble confectionnée pour l'événement. Celle-ci n'a plus la forme étroite des chasubles françaises copieusement critiquée par les protagonistes du mouvement archéologique ${ }^{53}$. Elle est allongée et élargie pour couvrir entièrement les épaules. Cette forme est d'ailleurs qualifiée dès cette époque d'archéologique. On trouve également le terme semi-gothique pour la distinguer de la forme gothique, encore plus ample, que Mgr de Dreux-Brézé n'a pas hésité à promouvoir quelques années plus tard, en 1853, lorsqu'il reçoit de Napoléon III un pontifical rouge dessiné par le même Arthur Martin et réalisé par le chasublier parisien Hubert Ménage ${ }^{54} 55$. 


\section{Une nouvelle réglementation pour le vestiaire liturgique}

44 l'idée d'une Église gallicane, doit être supprimée ainsi que d'autres habitudes très ancrées. Le mandement de 1853 instaurant la liturgie romaine est suivi de plusieurs ordonnances dont certaines concernent le costume. Selon le biographe du prélat, le chanoine Paul Pelletier, «Mgr de Dreux-Brézé se préoccupa beaucoup du costume ecclésiastique. Le rabat fut interdit et remplacé par le col romain, la queue de la soutane disparut. Les souliers à boucle étaient fortement conseillés, surtout aux offices. Il était strictement défendu de célébrer la sainte messe ou un office public en chaussures de bois. En voyage, un habit, plus proche de celui des laïcs, était toléré [...] mais noir et modeste ${ }^{56}$ ». Malgré ses aspirations en terme d'art religieux, l'évêque n'impose pas à son clergé une forme aussi ample que celle qu'il affectionne. Il se contente de la forme semi-gothique de la chasuble du sacre. Même les ornements de son prédécesseur, Mgr de Pons, lorsqu'ils sont toujours dignes d'être portés, sont élargis. Pour stopper toute polémique, au moment où la Sacrée Congrégation des Rites s'est prononcé catégoriquement, par la circulaire adressée en 1864 aux évêques, contre toute innovation ou rénovation de ce type, il se déplace lui-même à Rome avec une des chasubles semi-gothiques servant aux ordinations. Bien entendu, la position de Mgr de Dreux-Brézé qui a déjà eu l'occasion de montrer son attachement au Saint-Siège et qui entretient avec le pape Pie IX une amitié sincère, n'est pas remise en cause. Un maître des cérémonies pontificales, consulté, lui déclare qu'il peut «demeurer parfaitement tranquille et que la différence entre cette forme et la forme romaine était celles qui sont comptées pour rien ${ }^{57} »$. Une première lettre, datée du $1^{\text {er }}$ septembre 1864 et transmise au clergé du diocèse, informe de la décision prise par Rome. Mgr de Dreux-Brézé choisit donc la chasuble gothique «moyenne » car elle se rapproche davantage de celle de l'époque du concile de Trente et parce qu'il « préfère les délicatesses de l'obéissance à celles de l'archéologie ${ }^{58}$ ». Au cours du synode diocésain du 3 et 4 août 1865, la forme de la chasuble est définitivement fixée pour le diocèse de Moulins, conformément à celles en usage à la cathédrale. 


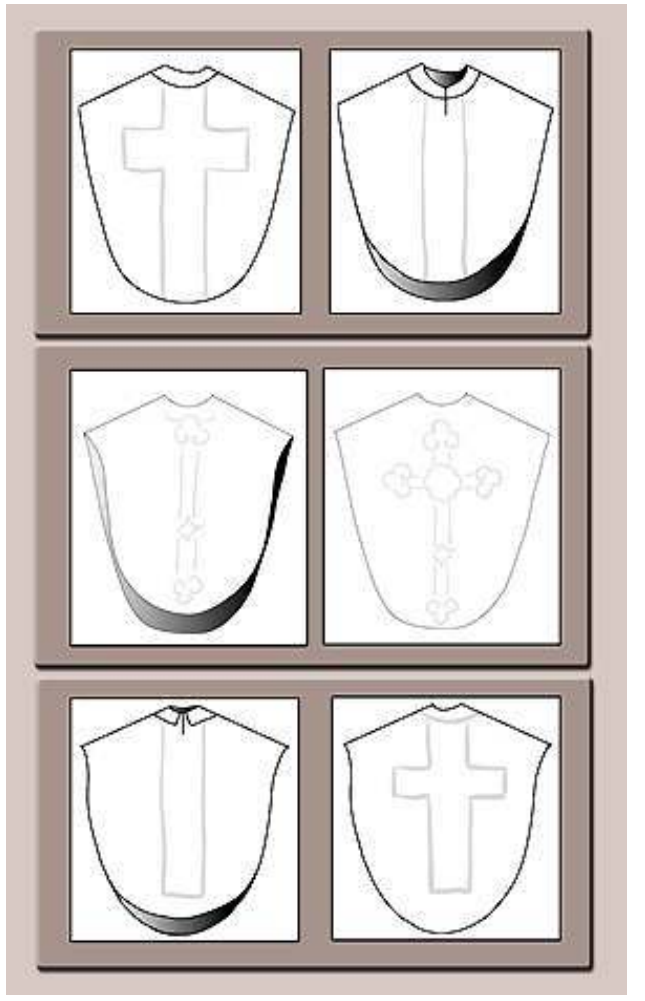

Variantes de la chasuble semi-gothique

Aurore Chatard, 2001-2005. (c) Aurore Chatard

L'avant doit désormais mesurer cent cinq centimètres de haut et l'arrière, cent vingt centimètres. Cinquante centimètres séparent le haut des épaules de l'extrémité, l'envergure est alors à peu près égale à un mètre (voir fig. $\mathbf{n}^{\circ}{ }^{12}$ ). Les prescriptions touchent également les dalmatiques, les tuniques dont les manches doivent être allongées et fermées, le surplis dont les manches sont élargies et le voile de calice qui doit le recouvrir entièrement et porter une croix en son centre. Contrairement à la chasuble, ceux-ci doivent parfaitement correspondre à l'usage romain. Ces nouvelles règles sont publiées sous forme de statuts synodaux l'année suivante. Les paroisses sont autorisées à conserver les anciens ornements de formes étroites pour les user mais tout nouvel achat est prohibé. Si les dimensions de la forme nouvelle sont très strictes, les fabricants s'accordent toutefois, sans pour autant déroger, la possibilité de quelques arrangements, notamment au niveau de l'échancrure des manches; un premier modèle ne présente aucune échancrure, un deuxième est échancré sur l'avant et un troisième sur l'avant et l'arrière. Comme l'encolure est étroite, l'addition d'un col est désormais possible (fig. $\mathbf{n}$ - 15).

Cette réforme n'a pas vraiment affecté le clergé hormis quelques prêtres un peu âgés. Cependant, le principal obstacle à franchir, et non le moindre, restait le dénuement évoqué plus haut dans lequel se trouvaient certaines paroisses, incapables de faire face à de nouvelles dépenses. 


\section{L'CEuvre des Églises pauvres}

47 À la suite des événements de 1848, Louise-Thérèse de Montaignac de Chauvance (1820-1885), religieuse à Paris, s'installe dans une propriété de famille en Bourbonnais. Elle y entreprend des actions pastorales auprès des populations rurales et visite de nombreuses paroisses dont l'extrême pauvreté l'émeut. À l'origine de la fondation des Oblates du Cœur de Jésus, elle met sur pied plusieurs œuvres charitables. En 1850 notamment, elle rassemble autour d'elle des femmes issues de la noblesse et de la bourgeoisie ayant du temps et un certain savoir-faire à offrir pour fonder l'œuvre des Églises pauvres. Celle-ci a pour vocation de répondre à une double nécessité de reconstituer le vestiaire liturgique déficient des églises les plus modestes et de constituer celui des paroisses nouvellement créées, le tout sans leur occasionner le moindre frais. Cette démarche n'est pas sans rappeler une action similaire menée à Paris en 1846 par le vicaire général François-Alexandre Roullet de La Bouillerie (1810-1882) qui crée, pour la France entière, l'Euvre des Tabernacles dont la finalité première est l'adoration du saint sacrement mais qui doit vite pallier l'insuffisance des sacristies pour le bon déroulement de celui-ci. D'après les sources concernant l'CEuvre des Églises pauvres auxquelles nous avons eu accès, à aucun moment, l'Cuuvre des Tabernacles n'est mise en relation avec elle, ni concernant un lien éventuel de filiation ni même à titre d'exemple. À aucun moment non plus Mgr de Dreux-Brézé n'informe le clergé et les fidèles de son diocèse de l'existence de cette œuvre nationale.

La première année, Mlle de Montaignac organise d'abord des réunions d'ouvrage à Montluçon et est en mesure de porter secours à cinq églises. En 1851, l'œuvre est officiellement approuvée par l'évêque. Un second centre d'activité est organisé à Moulins. Jusqu'en 1858, les dons en nature, tissus, dentelles, passementerie, etc. se montrant insuffisants, les fonds nécessaires aux achats sont dégagés d'une loterie organisée annuellement par les membres eux-mêmes. Ne pouvant répondre à une trop grande demande, à partir de cette date, Mgr de Dreux-Brézé décide de consacrer à l'œuvre la totalité de la recette de la quête du jour de la Fête-Dieu. Il sait combien la contribution d'une œuvre, dont les membres lui sont particulièrement dévoués, bien plus que ce qu'il pourrait attendre d'une œuvre à vocation nationale originaire d'un diocèse gallican, est essentielle pour un renouvellement efficace du vestiaire liturgique, effaçant ainsi plus rapidement les anciens usages. L'existence de cette œuvre est encore attestée cinquante ans après sa création. À l'heure actuelle, les Oblates du Cœur de Jésus de Montluçon ont laissé, dans les mémoires, le souvenir de leur grande habileté pour la réalisation de travaux d'aiguille.

\section{Conclusion}

Par l'examen des collections d'ornements liturgiques conservées dans les communes du sud du département de l'Allier et en comparaison avec d'autres travaux similaires, nous avons constaté que ceux-ci ont nettement évolué entre le $\mathrm{XVIII}^{\mathrm{e}}$ et le début du $\mathrm{XX}^{\mathrm{e}}$ siècle. Leur évolution est nourrie par l'enthousiasme du mouvement archéologique pour l'étude de l'art médiéval. Dans les années 1850-1860, plusieurs membres éminents de l'épiscopat français, sympathisants du mouvement, développent ce courant de pensée et, parmi eux, Mgr de Dreux-Brézé fait même figure de précurseur dans certains domaines 
d'application: l'adoption de la liturgie romaine et la modification des ornements liturgiques en sont les principales manifestations. Son arrivée à la tête d'un diocèse jeune dont la construction reste à achever et la longévité de son épiscopat lui ont permis plus facilement d'être à l'avant-garde et d'ancrer, par la suite, profondément ses idées malgré les quelques réticences rencontrées au début.

$\mathrm{Au} \mathrm{XIX}^{\mathrm{e}}$ siècle, le dynamisme des diocèses en pleine (re)construction comme celui de Moulins entraîne une forte demande en ornements liturgiques, favorisant encore la production textile lyonnaise déjà en plein essor. L'industrialisation des méthodes de production et la mise au point de nouveaux procédés techniques répondent à une clientèle toujours plus nombreuse et très variée quant aux moyens dont elle dispose. Toutes les paroisses, même les plus pauvres, se dotent d'ornements liturgiques afin de célébrer un culte suffisamment digne. Lorsqu'elles sont trop modestes ou à court de moyens, l'État apporte un soutien financier, contribuant ainsi aux achats. D'un autre côté, les cathédrales sont dotées de superbes ensembles dessinés par des membres éminents du mouvement archéologique tel Arthur Martin pour le Pontifical de Mgr de Dreux-Brézé. Dans le diocèse de Moulins, les efforts consentis par l'État sont relayés par ceux des fidèles que l'œeuvre des Églises pauvres cherche à concentrer en mettant à profit, dans le domaine de la confection, le savoir-faire et l'ingéniosité de paroissiennes dévouées et convaincues d'une nécessaire dignité attachée à la célébration du culte. L'évêque de Moulins n'a pas manqué de se servir de «ce bras armé d'aiguilles" pour diffuser les principes qu'il souhaite voir respecter: vestiaire composé de chaque couleur liturgique, forme semi-gothique, etc. Les soins apportés aux sacristies et aux églises grâce à cet élan général relayé sur place par les fabriques, dont l'établissement et le suivi de la gestion sont une préoccupation constante des deux premiers évêques du diocèse, marque durablement - et même, pourrait-on ajouter, jusqu'à nos jours - leur aspect et leur contenu.

51 En considérant son attachement pour le Saint-Siège et ses idées ultramontaines affichées, Mgr de Dreux-Brézé n'a pas choisi d'implanter systématiquement le modèle romain pour les objets du culte. Il n'a pas plus versé dans une restitution archéologique aveugle; il a choisi des formes d'ornements selon ses goûts sans entrer en contradiction avec les préceptes de Rome. Remarquons qu'au terme de son épiscopat, il n'a pas réussi à donner une impulsion suffisante pour générer une plus grande unité autour du Saint-Siège qui dépasserait les particularismes locaux, comme il l'avait certainement souhaité à ses débuts. Au contraire, il a modelé un diocèse de manière originale, caractérisé par des particularités, telle que la forme de la chasuble, ultérieurement connue pour lui appartenir en propre. Une étude globale des ornements liturgiques - et de manière plus générale, de l'art religieux - au XIX ${ }^{\mathrm{e}}$ siècle dans le diocèse de Moulins permettrait d'avoir une vision précise et juste de la véritable place de ce diocèse en France et de celle de son évêque, resté l'un des plus illustres de son temps. 


\section{NOTES}

1. Aribaud, Christine. Enquête sur les ornements liturgiques dans le diocèse de Toulouse, $\mathbf{X V I}^{\mathrm{e}}$-XIX ${ }^{\mathrm{e}}$ siècle. Histoire de l'art. Toulouse : Université de Toulouse-Le Mirail, 1989.

2. Voir dans la base Palissy : notice PM29000008.

3. Voir dans la base Palissy : notice PM77000369.

4. Chatard, Aurore. Les ornements liturgiques dans le diocèse de Moulins au XIX ${ }^{\mathrm{e}}$ siècle Moulins: Les Amis du patrimoine religieux en Bourbonnais, 2006. (disponible auprès de l'association)

5. Ces communes sont: Arronnes, Billy, Bost, Broût-Vernet, Châtel-Montagne, Chouvigny, Creuzier-Le-Neuf, Ébreuil, Échassières, Escurolles, Ferrières-Sur-Sichon, Jenzat, La Chabanne, La Chapelle, Lalizolle, Laprugne, Lavoine, Le Mayet-d'École, Le Mayet-de-Montagne, Magnet, Marcenat, Nades, Nizerolles, Saint-Bonnet-de-Four, Saint-Bonnet-de-Rochefort, Saint-Clément, Saint-Étienne-de-Vicq, Saint-Félix, Saint-Germain-des-Fossés, Saint-Nicolas-des-Biefs, Saint-Pont, Saulzet, Seuillet, Sussat, Valignat, Veauce et Vicq.

6. Bouchon, Chantal, Brisac, Catherine, Chaline, Nadine-Josette, Léniaud, Jean-Michel. Ces églises du XIX ${ }^{\mathrm{e}}$ siècle. Amiens : Encrage, 1993.

7. Conny, Adrien (de). Petit cérémonial romain rédigé d'après les sources authentiques. Paris : J. Lecoffre, 1854.

8. Barbier de Montault, Xavier. Le costume et les usages ecclésiastiques selon la tradition romaine, 2 tomes. Paris : Letouzey et Ané, 1899.

9. Thésaurus des objets religieux du culte catholique. Paris : Éd. du Patrimoine, 1999, p. 320.

10. Lesage, Robert. Chasuble. Catholicisme, hier, aujourd'hui, demain, tome 2. Paris : Letouzey et Ané, 1948. col. 1022-1023.

11. Viollet-le-Duc, Eugène. Dictionnaire raisonné du mobilier français de l'époque carolingienne à la Renaissance. Paris : Ernest Gründ, 1872, tome III, p. 142-148.

12. Lesage, Robert. Dalmatique. Catholicisme, hier, aujourd'hui, demain, tome III, 1947, col 427.

13. Barbier de Montault, Xavier. Le costume et les usages ecclésiastiques selon la tradition romaine, 2 tomes. Paris : Letouzey et Ané, 1899, tome 2, p. 77-78.

14. Berthod, Bernard, Hardouin-Fugier, Élisabeth. Dictionnaire des arts liturgiques, $\mathrm{XIX}^{\mathrm{e}}-\mathrm{XX}^{\mathrm{e}}$ siècle. Paris : les Éd. de l'Amateur, 1996, p. 364

15. Barbier de Montault, Xavier. Le costume et les usages ecclésiastiques selon la tradition romaine, 2 tomes. Paris : Letouzey et Ané, 1899, p. 364.

16. Thésaurus des objets religieux du culte catholique. Paris : Éd. du Patrimoine, 1999, p. 329.

17. Linges et ornements liturgiques, usage, symbolisme, matière, formes, couleurs, tome 2 . Paris : Maison de la Bonne Presse, 1915, p. 21.

18. Barbier de Montault, Xavier. Le costume et les usages ecclésiastiques selon la tradition romaine, 2 tomes. Paris : Letouzey et Ané, 1899, tome 2, p. 96.

19. Pascal, Jean-Baptiste Étienne. Origines et raison de la liturgie en forme de dictionnaire. Paris : Petit-Mont-Rouge, 1844, col. 748-750.

20. Barbier de Montault, Xavier. Le costume et les usages ecclésiastiques selon la tradition romaine, 2 tomes. Paris : Letouzey et Ané, 1899, tome 2, p. 165-168.

21. Berthod, Bernard, Hardouin-Fugier, Élisabeth. Dictionnaire des arts liturgiques, $\mathbf{X I X}^{\mathbf{e}}-\mathbf{X X}^{\mathbf{e}}$ siècle. Paris : les Éd. de l'Amateur, 1996, p. 452. 
22. Pastoureau, Michel. Une histoire symbolique du Moyen Âge occidental. Paris : Le Seuil, 2004, p. 151.

23. Duret, D. Mobilier, vases, objets et vêtements liturgiques. Étude historique. Paris : Letouzey et Ané, 1932, p. 164.

24. Traduit par Couren. Du Sacré mystère de l'autel. Paris : Plon, 1875.

25. Traduit par Barthélémy, Charles. Rational ou Manuel des divins offices de Guillaume Durand,... ou Raisons mystiques et historiques de la liturgie catholique. Paris : J. Frantz, 1848.

26. Le rose peut être utilisé deux fois dans l'année à la place du violet : le troisième dimanche de l'Avent, dit Gaudete, et le quatrième dimanche de Carême, dit Laetare.

27. Pascal, Jean-Baptiste Étienne. Origines et raison de la liturgie en forme de dictionnaire. Paris : Petit-Mont-Rouge, 1844, col. 441.

28. Pascal, Jean-Baptiste Étienne. Origines et raison de la liturgie en forme de dictionnaire. Paris : Petit-Mont-Rouge, 1844, col. 443.

29. Pascal, Jean-Baptiste Étienne. Origines et raison de la liturgie en forme de dictionnaire. Paris : Petit-Mont-Rouge, 1844, col. 441.

30. Barbier de Montault, Xavier. Le costume et les usages ecclésiastiques selon la tradition romaine, 2 tomes. Paris : Letouzey et Ané, 1899, p. 19.

31. Conny, Adrien (de). Les cérémonies de l'Église expliquées aux fidèles. Moulins: C. Desrosiers. Paris : Librairie de la propagande Haton, p. 63.

32. Conny, Adrien (de). Cérémonial romain rédigé d'après des sources authentiques. Paris : Méquignon Junior. Moulins : Comoy et Gilliet, 1858, p. 16.

33. Barbier de Montault, Xavier. Le costume et les usages ecclésiastiques selon la tradition romaine, 2 tomes. Paris : Letouzey et Ané, 1899, tome II, p. 21.

34. Barbier de Montault, Xavier. Le costume et les usages ecclésiastiques selon la tradition romaine, 2 tomes. Paris : Letouzey et Ané, 1899, tome II, p. 24.

35. Voir dans la base Palissy : notices IM65001177, IM05002076, PM05000584, IM05002290, etc.

36. Voir dans la base Palissy : notice PM31000598.

37. Voir dans la base Palissy : notices IM60000728, PM31000127, etc.

38. Dillmont, Thérèse (de). Encyclopédie des ouvrages de dames. Mulhouse: Thérèse de Dillmont Éditeur, 1886.

39. Voir dans la base Palissy : notices IM05002211, IM16000417, etc.

40. Archives communales de Creuzier-le-Neuf. Registre de fabrique.

41. Moulinet, Daniel. Le concordat de 1801 et ses implications dans le département de l'Allier. Nos églises bourbonnaises, oct. 2002, $\mathrm{n}^{\circ} 15$. p. 39-40.

42. Décret de la Sacrée Congrégation des Rites du 10 janv. 1597.

43. Archives paroissiales d'Ébreuil. Registre de fabrique de Chouvigny.

44. Berthod, Bernard, Hardouin-Fugier, Élisabeth. Dictionnaire des arts liturgiques, $\mathrm{XIX}^{\mathbf{e}}-\mathbf{X X}^{\mathbf{e}}$ siècle. Paris : les Éd. de l'Amateur, 1996, p. 28-35.

45. Saint-Martin, Isabelle. Les catalogues commerciaux du mobilier et des objets religieux des $\mathrm{XIX}^{\mathrm{e}}$ et $\mathrm{XX}^{\mathrm{e}}$ siècles. 2002. Cette étude, accompagnée de cinq catalogues illustrés est disponible sur le site du ministère de la Culture à l'adresse suivante: http:// www.inventaire.culture.gouv.fr/.

46. Archives communales de Creuzier-le-Neuf. Registre de fabrique.

47. [Catalogue commercial] Ornements d'église : Biais Aîné et Cie, vers 1900.

48. Berthod, Bernard, Hardouin-Fugier, Élisabeth. Dictionnaire des arts liturgiques, $\mathrm{XIX}^{\mathrm{e}}-\mathrm{XX}^{\mathrm{e}}$ siècle. Paris : les Éd. de l'Amateur, 1996, p. 28-35.

49. Archives diocésaines de Moulins, 1E1-2.

50. Conny, Adrien (de). Cérémonial romain rédigé d'après des sources authentiques. Paris : Méquignon Junior. Moulins : Comoy et Gilliet, 1858. 
51. Voir dans la base Mérimée : notice PA00093188.

52. Voir dans la base Palissy : notice PM03000635.

53. Voir dans la base Palissy : notice PM03000357.

54. Voir dans la base Palissy : notice PM03000353.

55. Berthod, Bernard, Picaud, Gérard. Pierres et ors, art et foi, trésor liturgique de la Cathédrale de Moulins. Thionne : Éd. du Signe, 1994.

56. Pelletier, Paul. Pierre Simon de Dreux-Brézé, Évêque de Moulins (1850-1893). Charroux : Cahiers du Bourbonnais, 1993, p. 93.

57. Archives diocésaines de Moulins. 1E1-2, Lettre au clergé, 18 septembre 1864.

58. Archives diocésaines de Moulins. 1E1-2, Lettre au clergé, 18 septembre 1864.

\section{RÉSUMÉS}

Depuis le concile Vatican II, la volonté de l'Église catholique de tendre vers une plus grande simplicité pour réduire la distance, tant physique que psychologique, entre ses ministres et l'ensemble des fidèles a contribué à abandonner certains fastes de la liturgie. Aujourd'hui, l'étude des ornements liturgiques rend compte de leur place au cours des rites et de l'attention portée à leur réalisation. Le XIX ${ }^{\mathrm{e}}$ siècle est souvent considéré comme l'âge d'or de leur confection. Une recherche menée dans le diocèse de Moulins a permis de mettre au jour la richesse et la diversité des collections de cette époque, ainsi que le renouvellement de la portée symbolique et politique dont ils ont fait l'objet.

Since the II Vatican Council, the wish of the Catholic Church for simplification in order to reduce the distance, both physically and psychologically, between their Ministers and all the believers, contributed to abandon some complex aspects of the liturgy. Nowadays, the liturgical ornaments studying, reports their role during the rites and the particular attention paid to their realization. The XIX ${ }^{\text {th }}$ century is often considered as the golden age of their confection. A research led in the diocese of Moulins, allowed to reveal the wealth and the variety of this period's collections, as well as the renewal of their symbolic and political mean. 


\section{INDEX}

Mots-clés : Adrien de Conny, antependium, bourse de corporal, cardinal Lothaire, chape de Saint-Bertrand-de-Comminges, chapes, chasuble, chasublier, Chelles, Concile de Trente, Concordat, conopée, dalmatiques, devant d'autel, Dom Guéranger de Solesmes, étole, étole dite de saint Pol de Léon, fabrique, fondation des Oblates du Cœur de Jésus, François-Alexandre Roullet de La Bouillerie, gallicanisme, Guillaume Durand, Hubert Ménage, île de Batz, insignes liturgiques, Jean-Baptiste Étienne Pascal, liturgie romaine, loi de Séparation 1905, Louise-Thérèse de Montaignac de Chauvance, maison Biais, maison Brun-Mériaud, maison Léon Bougron, manipule, Mgr Antoine de Pons de La Grange, Mgr de Dreux-Brézé, Mgr de Pons, Mgr Fornari, Mgr Pie, Moulins, mouvement archéologique, objets religieux, Euvre des Églises pauvres, Æuvre des Tabernacles, ornements liturgiques, pale, pape Innocent III, parement d'autel, parements liturgiques, pavillon, pentes de dais, père Arthur Martin, Pie IX, pluvial, Poussielgue-Rusand, pratiques cultuelles, réforme liturgique, Sacrée Congrégation des Rites, saint-sulpicien, ultramontanisme, vêtements liturgiques, voile de calice, voile de tabernacle, voile d'exposition, voile huméral, Xavier Barbier de Montault, concile Vatican II

\section{AUTEUR}

\section{AURORE CHATARD}

Historienne de l'art. achatard@yahoo.fr 